\title{
POST-DURAL PUNCTURE HEADACHE IN CAESAREAN SECTION- A COMPARATIVE STUDY USING 25 G QUINCKE, 27 G QUINCKE NEEDLE
}

\author{
Vaskar Majumdar¹, Joydeep Debnath²
}

${ }^{1}$ Assistant Professor, Department of Anaesthesiology, Agartala Government Medical College, Agartala. ${ }^{2}$ Senior Resident, Department of Anaesthesiology, Agartala Government Medical College, Agartala.

\section{ABSTRACT}

\section{BACKGROUND}

Post-spinal puncture headache (PSPH) is a well-known complication of spinal anaesthesia. It occurs after spinal anaesthesia induction due to dural and arachnoid puncture and has a significant effect on the patient's postoperative wellbeing. The present study was designed to compare the relation incidence of post-dural puncture headache after 25 G Quincke and 27 G Quincke needle during spinal anaesthesia in cases of caesarean section.

\section{MATERIALS AND METHODS}

The study was carried out on 100 ASA grade I and II parturients in the Department of Anaesthesiology at AGMC \& GBP Hospital. Patients were divided into two groups in which 50 patients received spinal anaesthesia with 25 gauge Quincke needle \& 50 patients received spinal anaesthesia with 27 gauge Quincke needle.

\section{RESULTS}

The incidence of post-dural puncture headache was highest in group I and lowest in group II, although the differences being statistically insignificant. All the patients who developed PDPH had mild degree of headache. $25 \mathrm{G}$ needle was associated with the higher incidence of PDPH than 27 G needle candidates.

\section{CONCLUSION}

So we can conclude from our study that incidence of PDPH is comparatively more with Quincke 25 G needle than 27 G Quincke needle, whereas failure rate for successful neuraxial block is little more with $27 \mathrm{G}$ needle. But for most of them who developed PDPH, it lasted less than 24 hours.

\section{KEYWORDS}

Post-dural Puncture Headache, Caesarean Section, 25 G Quincke Needle, 27 G Quincke Needle.

HOW TO CITE THIS ARTICLE: Majumdar V, Debnath J. Post-dural puncture headache in caesarean section- A comparative study using 25 G Quincke, 27 G Quincke needle. J. Evolution Med. Dent. Sci. 2017;6(5):398-401, DOI: 10.14260/Jemds/2017/89

\section{BACKGROUND}

Spinal anaesthesia also called subarachnoid block is a form of regional anaesthesia and a kind of neuraxial block involving injection of opioids, local anaesthetics or other permissive drug into the subarachnoid space.(1,2) The first spinal anaesthetic was delivered by an accident. Its inception can be traced back in the late 19th century by James Leonard Corning. He reported on spinal anaesthesia in 1885 for the first time. The first planned spinal anaesthesia was administered by August Bier in 1898. He had personal knowledge of the symptoms of post-dural puncture headache (PDPH). Bier reported complications including back and leg pain, vomiting and headache. Even at this early stage, he had associated the loss of cerebrospinal fluid with post-spinal headache. $(3,4)$

It has a very rapid onset and provides a dense neural block which can produce highly effective pain relief for a wide variety of indications and may decrease patient morbidity

Financial or Other, Competing Interest: None.

Submission 10-12-2016, Peer Review 03-01-2017,

Acceptance 09-01-2017, Published 16-01-2017.

Corresponding Author:

Dr. Vaskar Majumdar,

Assistant Professor,

Department of Anaesthesiology,

AGMC \& GBP Hospital,

Tripura-799006.

E-mail: jdebnath797@gmail.com

DOI: $10.14260 /$ jemds $/ 2017 / 89$

\section{(c) (i) $(-$}

after major surgery, moreover failures are very infrequent. $(1,2)$

Randomised trials (RCTs) or observational studies that obtain the incidence of PDPH, evaluating the different individual factors or techniques on PDPH incidence or comparing the effect of different spinal needles (gauge and design) in the incidence or prevalence of PDPH have been reviewed.

The incidence of PDPH does not occur in all patients who received lumbar puncture for diagnostic or anaesthetic reasons and is found to be more common after caesarean section in young parturients. ${ }^{1,2} \mathrm{~A}$ few decades ago less refined and thicker spinal needles were being used and the incidence of PDPH was high.2,3,4,5 But within the last 15 years more refined and thinner needles of $24 \mathrm{G}$ to $28 \mathrm{G}$ have been used more often and the incidence of PDPH is grossly reduced to less than $3 \%$ to $5 \%$.

The present study was designed to compare the incidence of post-dural puncture headache after $25 \mathrm{G}$ Quincke and $27 \mathrm{G}$ Quincke needle during spinal anaesthesia in cases of caesarean section.

\section{MATERIALS AND METHODS}

After approval of hospital ethical committee, the study was carried out on 100 ASA grade I and II female parturients in the Department of Anaesthesiology at AGMC \& GBP Hospital. The patients were selected randomly from the age group of 20-35 years having a pregnancy of at least 36 weeks 
gestation, detailed written informed consent was taken. Patients were divided into three groups, each group consisting of 50 patients.

Study Design: An observational study.

Study Area: Agartala Govt. Medical College and GBP Hospital. Study Period: Oct. 2012 to Oct. 2015.

\section{Sample Size}

Group I: 50 Patients who received spinal anaesthesia with 25 gauge Quincke needle.

Group II: 50 Patients who received spinal anaesthesia with 27 gauge Quincke needle.

\section{Inclusion Criteria}

- Patients of ASA-I and ASA-II category; within 20-35 years of age having a pregnancy of at least 26 weeks gestation with a single uncompromised foetus and uncomplicated pregnancy.

\section{Exclusion Criteria}

- CVS/CNS disorders, neuromuscular diseases (e.g. myopathies and neuropathies), hypovolaemia, acid-base disturbances and electrolyte imbalance, obesity.

Inj. Ranitidine 1 ampoule and Inj. Metoclopramide 1 ampoule were given IV slowly preoperatively 1 hour before surgery. In the operating room, ECG and heart rate were monitored by a cardioscope. Blood pressure, Pulse oximetry was monitored. Patient was preloaded with 500 cc Ringer lactate solution prior to spinal anaesthesia. Spinal anaesthesia was performed under proper antiseptic condition using a midline approach at the L 2-3 or L 3-4 interspace using one of the above spinal needles and $0.5 \%$ hyperbaric bupivacaine, dose $30 \%$ less to $0.3 \mathrm{mg} / \mathrm{kg}$ was injected. After withdrawal of the needle, the patient was turned to the supine position with left uterine displacement. Level of sensory blockade and changes in parameters like heart rate, BP were recorded. Solution of Ringer lactate, GNS, colloid and blood was transfused as maintenance fluid and also according to the blood loss. Hypotension was treated with $6 \mathrm{mg}$ Inj. Mephentermine given intravenously. Complications like nausea, vomiting, bradycardia, respiratory depression, skin reaction were managed symptomatically.

A different anaesthesiologist not knowing the type of needle used did postoperative observations. Patients were interviewed on day 1, 2, 3, 4, 5 and were questioned as regard to headache, its severity, location, character, duration, associated symptoms like nausea, vomiting, auditory and ocular symptoms.

Post-dural headache, when present was treated with bed rest, $500 \mathrm{cc}$ of $5 \%$ dextrose as an additional fluid and Inj. Diclofenac $75 \mathrm{mg}$ IM. The success and failure rate associated with needle insertion was also recorded. At the end of the study, data were compared and statistically analysed using paired ' $\mathrm{t}$ ' test and chi-square tests.
RESULTS

\begin{tabular}{|c|c|c|}
\hline & Group 1( n=50) & Group 2( n=50) \\
\hline Age(years) & $23.6(2.9)$ & $23.1(2.7)$ \\
\hline Weight $(\mathrm{kg})$ & $56.9(8.9)$ & $52.8(5.2)$ \\
\hline Height $(\mathrm{cm})$ & $152.7(2.5)$ & $152.1(2.2)$ \\
\hline \multicolumn{2}{|c|}{ Table I. Demographic Distribution } \\
\hline
\end{tabular}

The failure rate with the needle insertion was $0 \%, 4 \%$. The difference in failure rate between groups was not statistically significant.

\begin{tabular}{|c|c|c|}
\hline Nature & Group I & Group II \\
\hline Elective/Emergency Indication & $20: 30$ & $22: 28$ \\
\hline Failed Progress & $26(52 \%)$ & $20(40 \%)$ \\
\hline Contracted Pelvis & $12(24 \%)$ & $14(28 \%)$ \\
\hline B.O.H. & $06(12 \%)$ & $06(12 \%)$ \\
\hline Obstructed Labour & $04(8 \%)$ & $04(08 \%)$ \\
\hline Post Term - & $02(4 \%)$ & $06(12 \%)$ \\
\hline Table 2. Indication of Caesarean Section \\
\hline
\end{tabular}

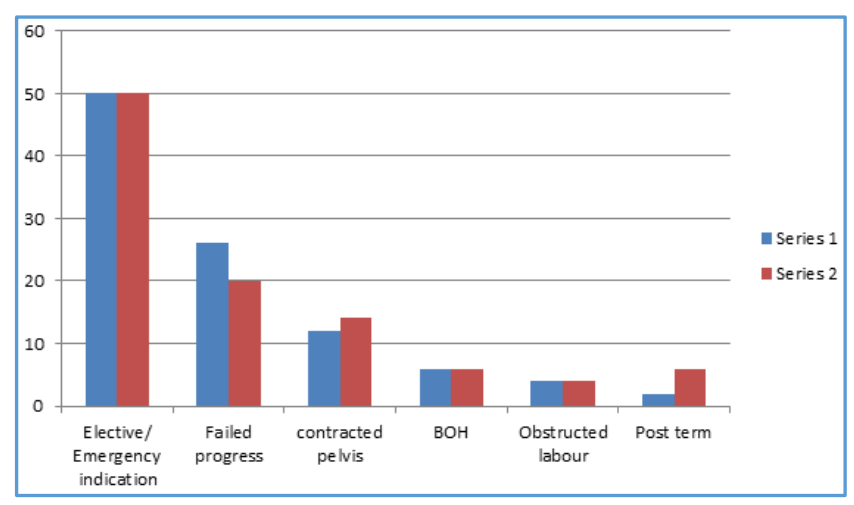

Chart 1. Indication of Caesarean Section

\begin{tabular}{|c|c|c|}
\hline & Group I No. (\%) & Group II No. (\%) \\
\hline Incidence & $05(10 \%)$ & $03(6 \%)$ \\
\hline Onset & & \\
1st day & $3(33.33 \%)$ & $1(11.11 \%)$ \\
2nd day & $1(11.11 \%)$ & $2(22.22 \%)-$ \\
3rd day & $1(11.11 \%)$ & \\
4th day & & \\
\hline Location & & $1(11.11 \%)$ \\
Frontal & $4(44.44 \%)$ & $1(11.11 \%)-$ \\
Generalised & $2(22.22 \%)$ & \\
Occipital & $1(11.11 \%)$ & 03 \\
\hline Severity & & \\
Mild & & \\
Moderate & 05 & 03 \\
Severe & & \\
\hline Duration & & \\
$<24$ hours & 04 & \\
25 - 48 & 01 & \\
48 hours & & \\
\hline \multicolumn{2}{|c|}{ Table 3. Post-Spinal Headache }
\end{tabular}




\section{Incidence of PDPH (Observed in 8 Patients out of 100}

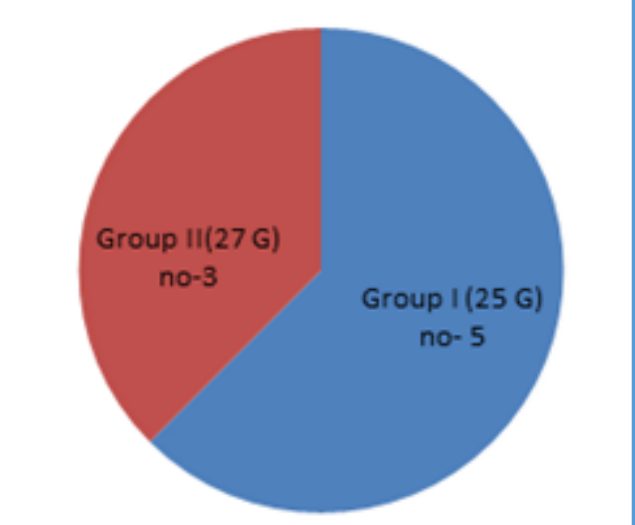

Chart 2. Incidence of Post-Spinal Headache

Of the 100 patients, 8 were complicated by headache postoperatively. The overall incidence of PDPH was $10 \%$ in group I, 6\% in group II. The difference in PDPH between groups was not statistically significant. The mean duration of headache was found to be 27.77 hours. In 7 patients, out of 8 , the duration of headache lasted less than 24 hours. In only one patient, the duration of headache was up to 48 hours. All the patients who developed PDPH had mild headache. In 7 out of 8 patients who had PDPH in the present study, the location was frontal region. Only one patient had generalised headache. Onset of headache was 24 hours to 72 hours after dural puncture.

\section{DISCUSSION}

There is considerable evidence that the PDPH is due to a low CSF pressure consequent to seepage of CSF through the dural puncture hole and choroid plexus is unable to secrete sufficient fluid to maintain the CSF pressure. Moreover, the negative pressure in the epidural space may draw CSF from subarachnoid space. Cerebrospinal fluid leakage from the dural hole produces CSF hypotension, which in turn leads to intracranial venous dilatation resulting in an increase in brain volume in the upright position. There occurs a difference in CSF volume and also pressure differential between the intracranial and intravertebral part of the subarachnoid space. Venous dilation and compensatory increase in brain volume will result in brain sag which in turn will exert traction and stimulate pain sensitive anchoring structures like dural vessels, basal dura and tentorium cerebelli, causing post-spinal headache. Larger the hole in dura mater, more will be the leakage of CSF and longer the time required for repair. The number of holes in the dura also makes a difference in the loss of CSF. It takes about two weeks or more for the holes to seal. 6,7

The overall incidence of distressing post-spinal headache has varied from $0 \%$ to $37.2 \%$ as reported by various authors.(8,9) The most important factor contributing to the higher incidence of PDPH was the gauge and type of needles used. Thicker the needle, and more traumatic the type of needle (cutting type), more the incidence of post-spinal headache.2,3 The observed incidence of PDPH in our study was in accordance with the above finding. The incidence of PDPH was $10 \%$ in group I, $6 \%$ in group II.
The difference is statistically insignificant. In a study by Hwang7 (1991), the incidence of headache was 1.06\%, 3.6\% and $2.08 \%$ with $25 \mathrm{G}$ Whitacre, $25 \mathrm{G}$ Quincke and $26 \mathrm{G}$ Quincke needle respectively. Mean duration of headache was found to be 27.77 hours (range 24-48 hours). In 7 out of 8 patients, who had PDPH in the present study, the duration of headache lasted less than 24 hours. In only one patient, the duration of headache was up to 48 hours.

In a study by Lynch ${ }^{10}$ (1991), the mean duration of headache was 48 hours (range 24-64 hours) and 57.5 hours (range 8-80 hours) in the 25 and 22 gauge groups respectively. In the 7 out of 8 patients who had PDPH, the location of headache was frontal region. Only one patient had generalised headache.

In a study by Jones $\mathrm{R}, 11$ the incidence of frontal, parietal occipital and generalised were 50.0\%, 1.4\%, 25.0\% and $23.6 \%$ respectively. All the patients who developed PDPH had mild headache, none of the patients developed a severe headache or neurological sequelae because of the use of finer gauge of the needle, proper hydration and immediate treatment with bed rest, hydration and analgesics.

In a study by Shutt et al, ${ }^{8}$ onset of headache was from 18 to 57 hours after dural puncture. Once the patient had headache, he was instructed to take complete bed rest.

All the patients received Inj. Diclofenac Sodium, intramuscular (75-mg) 8 hourly and hydration therapy with $5 \%$ dextrose $500 \mathrm{cc}$ as an additional fluid within a period of one hour.

All the patients responded with this treatment and did not complain of headache after 24 hours, except one, who required a similar pattern of treatment for another 24 hours. None of the patients required epidural blood patch. There is a universal consensus about the fact that the thicker the lumbar puncture needles, the higher could be the incidence of PDPH. A cutting type of needle inserted through the dural wall tears off a number of fibres in the wall and a permanent opening in it is ensured.12,13,14 The puncture site has typical crescent like appearance produced by the cutting type of needle. The anatomical feature of dura is such that longitudinal dispersion of its fibre plus a copious interspersion of elastic fibres keeps the hole open once the dural fibres are cut.

Cappe $^{13}$ (1960) suggested the use of a pencil point lumbar puncture needle and the tip of the pencil point needle separates the longitudinal dural fibres without producing serious injury. When the needle is withdrawn, the fibres return to a state of close approximation. In the present study, bevel of the needle was inserted parallel to the longitudinal dural fibres, so that these fibres are separated and are not damaged and a narrow slit like opening is obtained, with a greater tendency to contraction and plugging of the hole, decreasing the leakage of CSF.

In a study by Lybecker et $\mathrm{al}^{14}$ (1990), the incidence of PDPH among patients in whom the bevel was inserted parallel to the longitudinal dural fibres was 0.56 times the incidence among patients in whom the bevel was inserted perpendicular to the longitudinal dural fibres. There are a few studies, which examine the technical difficulties involved in the use of different spinal needles. In a study by Dittmann and Renkl 12 (1989) the failure rate was $1.4 \%$ and $1.2 \%$ in 29 and 26 gauge groups respectively. 
In another study by Shutt et $\mathrm{al}^{8}$ (1992), the failure rate was $2 \%$ and $6 \%$ with $22 \mathrm{G}$ and $25 \mathrm{G}$ Whitacre needle. In the present study, $25 \mathrm{G}$ Quincke needle was associated with the greatest incidence of successful dural puncture following a single needle insertion (100\%). All the patients were hydrated in a similar manner.

Almost all the recent studies have expressed the opinion that early ambulation $(11,15)$ does not enhance the incidence of PDPH nor does it increase the severity of the syndrome. However, in the present study all the patients were instructed to remain in supine position for 24 hours in the postoperative period.

Age of the patient did not play any significant role in our study since all the patients in varying groups were of the similar age groups. However, the incidence is found to be lower in older patients. ${ }^{2}$ In older patients, an altered pain sensitivity of vascular pain receptors and narrowed route of escape of CSF from the epidural space are assumed to be the explanation for lower incidence.

In a study by Rasmussen et $\mathrm{al}^{16}$ (1989), the incidence of PDPH in young patients was $27.6 \%$ with $20 \mathrm{G}$ and $12.6 \%$ with $25 \mathrm{G}$. In the elderly patients, incidence of headache with $20 \mathrm{G}$ and $25 \mathrm{G}$ needles was $10.8 \%$ and $7.8 \%$ respectively.

The incidence of PDPH is more common among women than men, particularly prone are the parturients, (1,2) because of the reduction of both the intra-abdominal and epidural pressure after delivery, thereby promoting extra leakage of CSF than usual. Sex bound difference is caused by emotional and hormonal factors.

\section{CONCLUSION}

Several factors seem to predispose a patient to develop PSPH after spinal anaesthesia including age, gender, number of attempts, and needle size, history of previous PSPH or chronic headache. Decreasing the gauge $(G)$ of needle applied for spinal anaesthesia may be a logical solution to decrease the incidence of PSPH. Therefore, a balance has been struck between the risk of PDPH and technical failure. Most experts agree that 25- $27 \mathrm{G}$ needles probably represent the optimum needle size for spinal anaesthesia.

So we can conclude from our study that incidence of PDPH is comparatively more with Quincke $25 \mathrm{G}$ needle than 27 G Quincke needle, whereas failure rate for successful neuraxial block is little more with $27 \mathrm{G}$ needle. But for most of them who developed PDPH, it lasted less than $24 \mathrm{hrs}$.

\section{REFERENCES}

[1] Krueger JE, Stoelting VK, Graf JP. Etiology and treatment of post-spinal headaches. Anesthesiology 1951;12:47785.

[2] Vandam LD, Dripps RD. Long term follow-up of patients who received 10,098 spinal anesthetics. Syndrome of decreased intracranial pressure (headache and ocular and auditory difficulties). Journal of the American Medical Association 1956;161(7):586-91.
[3] Kaukinen S, Kaukinen L, Kannisto K, et al. The prevention of headache following spinal anaesthesia. Ann Chir Gynaecol 1981;70(3):107-11.

[4] Meyer-Hamme K, Stratmann D, Watermann WF, et al. Postspinal headache-a clinical problem. Reg Anaesth 1979;28(10):77-80.

[5] Dahl JB, Schultz P, Anker-Moller E, et al. Spinal anaesthesia in young patients using a 29 gauge needle: technical considerations and an evaluation of postoperative complaints compared with general anaesthesia. Br J Anaesth 1990;64(2):178-82.

[6] Flaatten H, Rodt SA, Vamnes J, et al. Postdural puncture headache. A comparison between 26- and 29- gauge needles in young patient. Anaesthesia 1989;44(2): 147-9.

[7] Hwang JJ, Ho ST, Wang JJ, et al. Post-dural puncture headache in caesarean section: comparison of 25-gauge Whitacre with 25- and 26-gauge Quincke needles. Acta Anesthesiol Sin 1997;35(1):33-7.

[8] Shutt LE, Valentine SJ, Wee MYK, et al. Spinal anaesthesia for caesarean section: comparison of 22 gauge and 25 gauge Whitacre needle with 26 gauge Quincke needles. Br J Anaesth 1992;69:589-94.

[9] Flaatten H, Reader J. Spinal anaesthesia for outpatient surgery. Anaesthesia 1985;40(11):1108-11.

[10] Lynch J, Krings-Earnst I, Strick K, et al. Use of a 25-gauge Whitacre needle to reduce the incidence of postdural puncture headache. Br J Anaesth 1991;67:690-3.

[11] Jones R. The role of recumbency in the prevention and treatment of postspinal headache. Anaesthesia and analgesia 1974;53(5):788.

[12] Dittman M, Renkl F. Spinal anaesthesia with extremely fine needles. Anesthesiology 1989;70(6):1035-6.

[13] Cappe BE, Park NM. Prevention of postspinal headache with a 22-gauge pencil point needle and adequate hydration. Anaesthesia and analgesia current Researches 1960;39(5):463-5.

[14] Lybecker H, Moller JT, May O, et al. Incidence and prediction of postdural puncture headache. A prospective study of 1021 spinal anesthesias. Anesth Analg 1990;70(4):389-94.

[15] Hafer J, Rupp D, Engel J, et al. The effect of needle type and immobilization on postspinal headache. Anaesthesist 1997;46(10):860-6.

[16] Rasmussen BS, Blom L, Hansen P, et al. Post spinal headache in young and elderly patients. Two randomized, double-blind studies that compare 20- and 25-gauge needles. Anaesthesia 1989;44(7):571-3. 